\title{
Occupational Burnout Research and Analysis of Vocational School Teachers under Comprehensive Incentive Model Perspective
}

\author{
Zhang Guojing \\ Liao Ning Urban Construction Technical College
}

\begin{abstract}
Based on Stephen Robbins Comprehensive Incentive Model, the author analyzes the causes of teachers' job burnout and puts forward preventive measures by method of sampling questionnaire survey and interview on part of Liaoning vocational college teachers from personal goal, individual effort, the individual performance and organizational reward.
\end{abstract}

Key Words- Comprehensive Incentive Model; Vocational College;Teachers;Job Burnout

\section{INTRODUCTION}

Higher vocational colleges are cradle of talent training, education teaching effect of teachers directly affects the quality of talent, thus specific solutions to higher vocational college teachers' job burnout phenomenon is imminent.

\section{Analysis On Vocational College Teachers' Job Burnout Factors}

The author conducted a sample survey on 300 teachers of Liaoning vocational colleges based on related theory of Stephen Robbins Comprehensive Incentive Model, among whom 243 teachers had ever felt burnout accounting for $81 \%$ of the total and 57 had not produced a burnout accounting for $19 \%$. The author had a further analysis and survey on 243 teachers who had ever produced burnout so as to find key factors that affect burnout and propose practical measures to alleviate or even eliminate the phenomenon of burnout.

\subsection{Individual efforts are not effectively motivated}

According to the survey results, there exists significant relationship between individual effort and burnout. the overwhelming majority of teachers choose absolutely matched and mostly matched on work pressure and a lack of learning opportunities, as shown in figure 1 


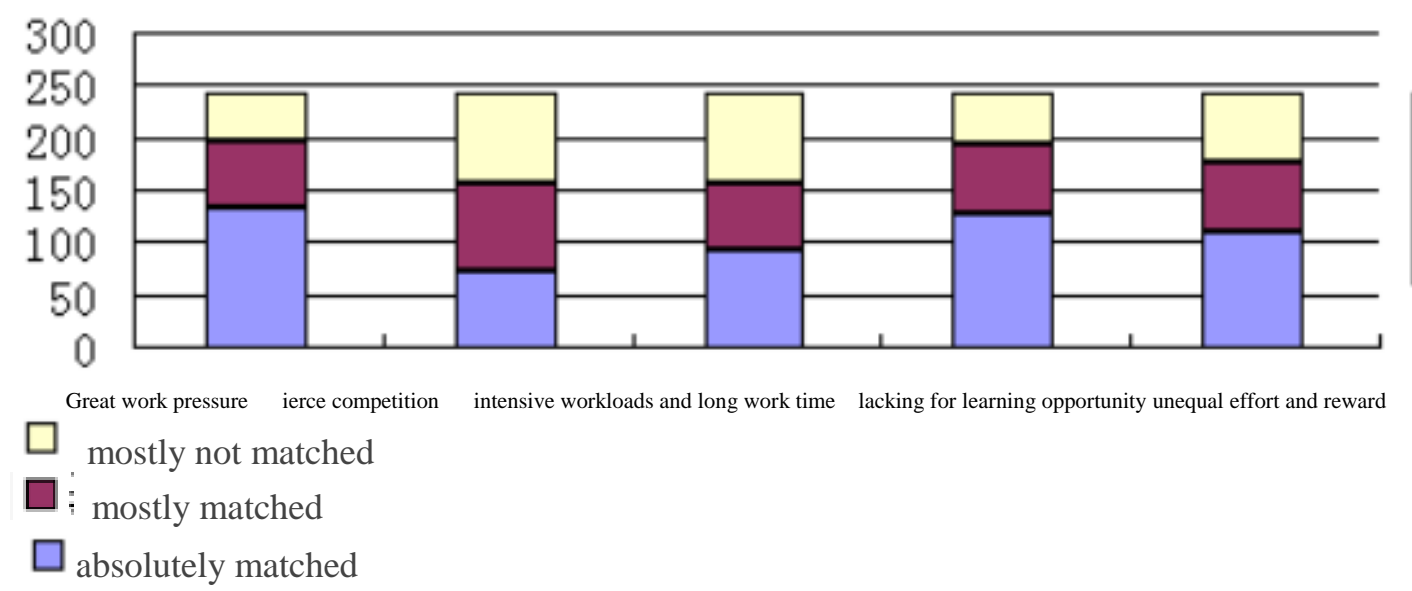

Individual efforts

Figure 1:relationship between Individual efforts and vocational burnout

Faced with increasing competition, teachers have dual pressures of work and life. They can only improve and enrich themselves and keep on learning to survive in the competition. Intensive workload and long working hours are common for teachers. Most teachers expect to realize their own social values through their own efforts and their social achievements can be recognized by school and parents, but teachers' efforts are often not a positive relationship with their reward. They are neglected and resented, which leads to diminishing confidence and teaching passion.

\subsection{Individual performances are not fairly and impartially treated}

Data analysis show that between relationship of individual performance and job burnout teachers think that the most closely factor is a lack of reasonable performance evaluation criteria, for $90 \%$ of burnout teachers agree with this option,as shown in figure 2 .

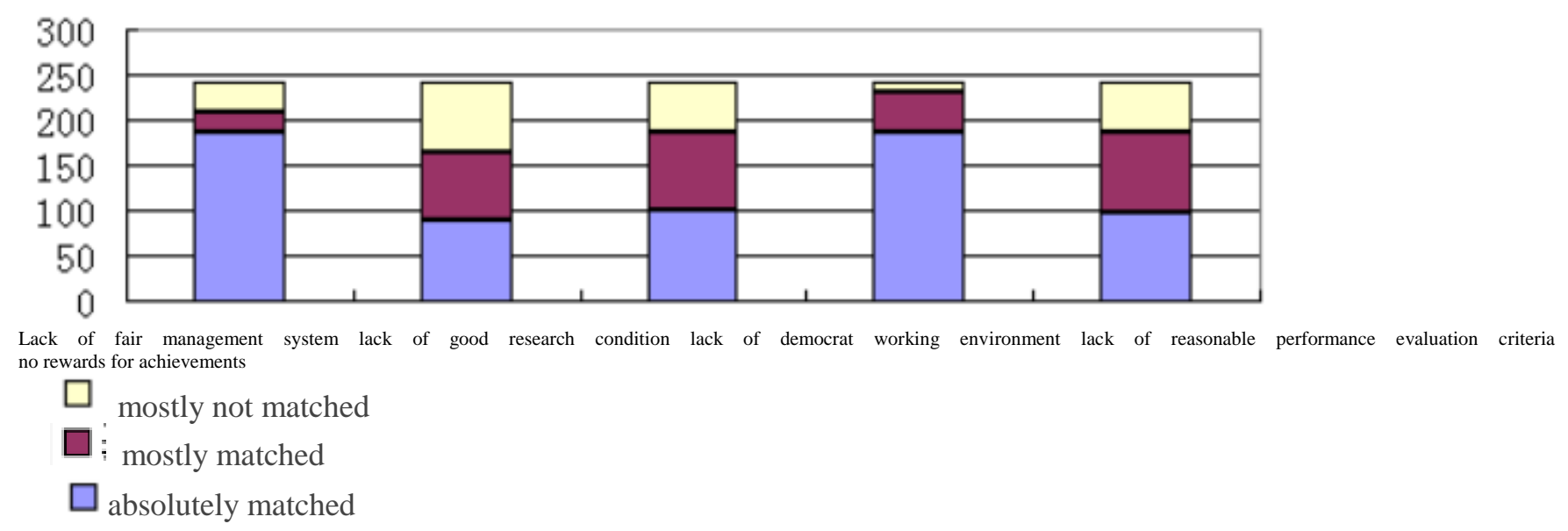

individual performance

Figure 2: relationship between individual performance and job burnout 
Previous assessment standards emphasize quantification of workload while considering all the work as results that can be calculated by figures without taking into account the special nature of the vocation of teachers. As a educational profession, teachers are not only to cultivate students intellect, but also to develop their moral education. As the saying goes, learn to behave before learning to do. Being spiritual wealth,teacher's words and deeds affect students' life ${ }^{1}$. And this can not reflected precisely in the evaluation of the existing school system,because of the lack of a new set of school performance evaluation standards, so teachers burnout intensifies, which is not conducive to the development of teachers' personal career.

\subsection{Group rewards is difficult to meet individual needs}

Teachers who choose absolutely matched and mostly matched on unfair teaching awards account for $100 \%$, therefore, fair rewards and burnout exist a positive correlation, as shown in Figure 3.

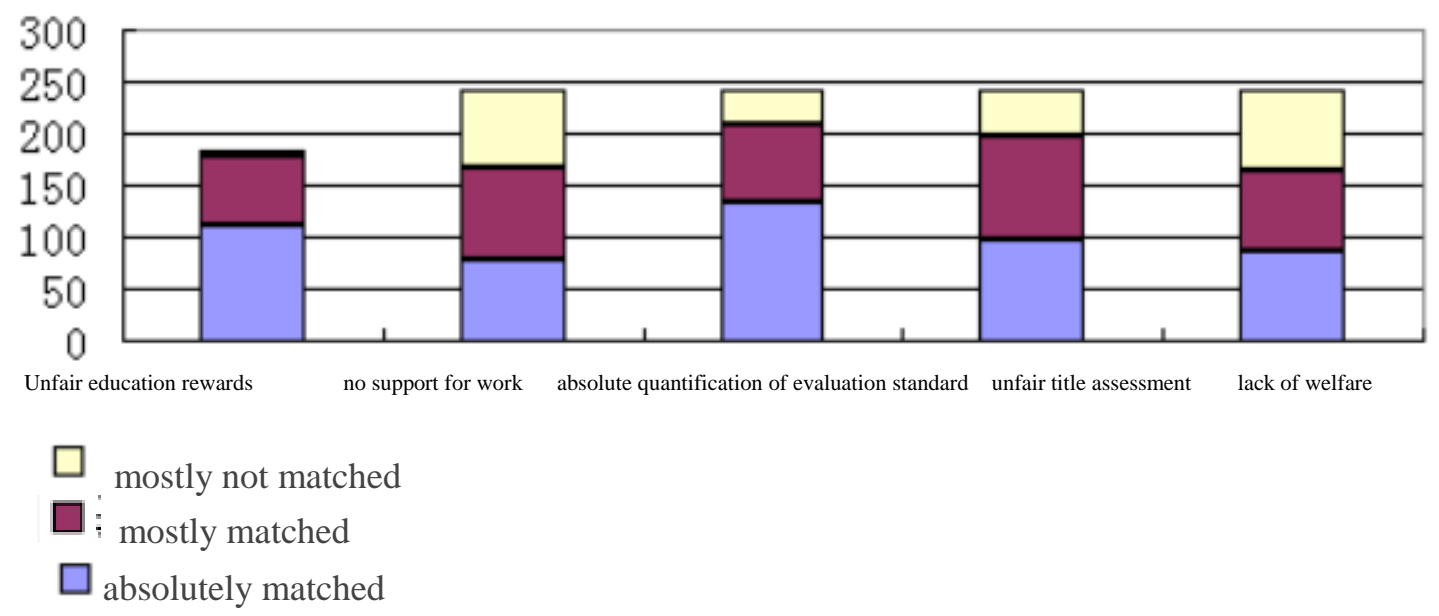

Group Rewards

Figure 3: Relationship between Group Rewards and job burnout

Most teachers express their willingness to enhance themselves by updating education concepts, innovating education method and desire for the opportunity to compile textbooks in line with the characteristics of students by combining their teaching experience. They also cherish the opportunity for further education abroad provided by school, but the heavy teaching task greatly reduce the chance of teaching training and education and greatly weaken the enthusiasm of teacher learning.

\subsection{Indistinct personal goal setting}

Relationship between personal goals and career burnout reflects in a lack of career planning, work lost without direction and lack of motivation and passion, etc. As shown in Figure 4: 


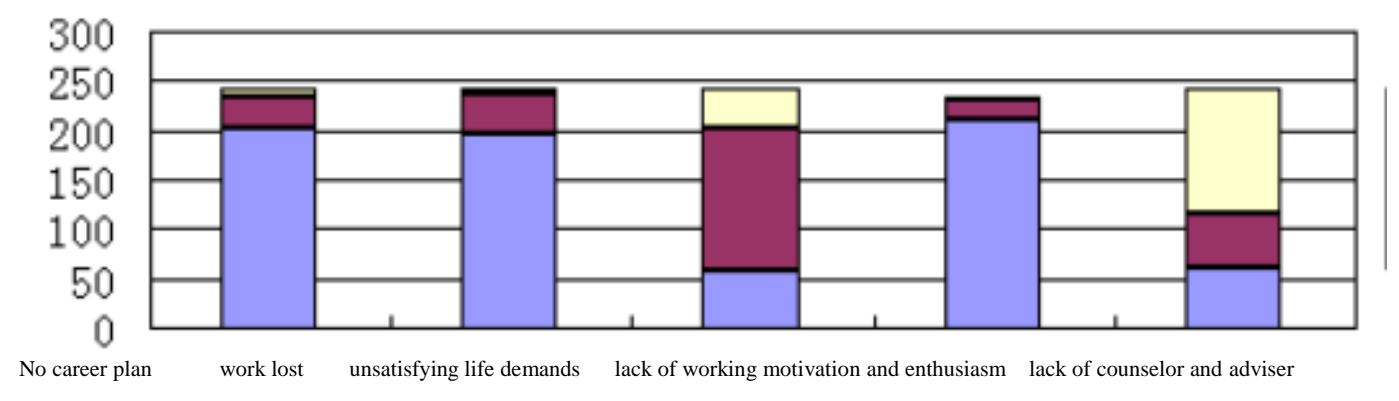

mostly not matched

mostly matched

absolutely matched

personal goals

Figure 4:Relationship between personal goals and career burnout

The survey shows that the majority of teachers in vocational colleges are not very clear about the school development planning objectives and path. They are only the executors of tasks assigned by the leadership without understanding which goal is to achieve and which stages is to realize.It precisely hamper the setting of teachers' personal goals, and this asymmetry is a serious impediment to achieve personal goals or them. ${ }^{2}$

\section{The incentive countermeasures to solve the problem of job burnout}

\subsection{Promote teachers' learning ability}

\subsubsection{Improve teachers' career planning ability}

Career planning is the basis for developing career goals. The teacher first make a career planning with their own conditions and the actual situation of life, that is to say career planning is the ultimate goal setting for themselves.According to survey results, most teachers lack a sense of direction at work, for they feel that there is no goal. Thus in the survey, the majority of teachers believe that the lack of career planning, work without a sense of direction and a lack of motivation and passion have great relationship with burnout. Designing of a reasonable career planning is important for coping with burnout problem science.

\subsubsection{Provide opportunity for advanced study}

School is a place for second promotion for teachers. The survey shows that since many teachers teach, they often feel a increasingly scarce of knowledge and their stock of knowledge is difficult to meet social professional needs for talent of the new era. They are very eager to learn again to fill the vacancy in knowledge, so when paying attention to the employment rate and enrollment rate, vocational college should also intensify efforts to provide teachers with the opportunity for learning to help teachers' self-improvement, provide teachers ample time to fill the knowledge gaps and improve their knowledge system as well as improve teachers' knowledge and practical experience through distance learning or business visits and other methods.

\subsection{Establish individual performance appraisal system for teachers}

\subsubsection{Strengthen Performance Management}

The school should popularize knowledge of performance management from the leadership to teacher and understand the role of performance management. To develop a good performance evaluation standards need to update their performance management concept first, which is the first step in setting a 
successful performance appraisal system.

\subsubsection{Improve performance appraisal standard}

School should focus on a detailed analysis of each faculty positions and determine its responsibility range to provide scientific and rational basis for performance evaluation standards.

\subsubsection{Set clear appraisal objective}

In the process of assessment, work of teachers' attitude, working ability, work efficiency and other aspects should be defined to make a scientific, rational and transparent assessment. Develop results feedback system, promptly convey examination results to teachers and public school teachers' performance appraisal result. Furthermore, encourage and reward teachers getting high test results while helping those who get low test results find their own shortcomings and even make improvement so as to achieve the purpose of performance appraisal.

\subsection{Make objective and fair group reward system}

\subsubsection{Promote rewards methods diversification}

As positive reinforcement in psychology, Incentive reward should be diversified. School should enact detailed incentives regulations to develop scientific reward. Based on Maslow's hierarchy of needs theory, different reward methods should be implemented according to different needs of teachers. If the teacher live in shabby conditions, the urgent need for teachers is financial reward. if the teacher living in good condition, then the teacher are more focused on psychological needs.

\subsubsection{Well-publicised spiritual reward}

Currently, school spirit incentive is in need of authority and can not achieve demands of self-realization of teachers. To some extent, if spiritual reward play the biggest role, the effect is much larger than the effectiveness of material reward, so schools can not ignore the importance of spiritual rewards. School should use various media to improve the attractiveness of the spiritual rewards on teacher education and teaching and stimulate the internal driving force of teachers so as to avoid burnout generation.

\subsection{Improve career goals guidance Through efforts}

\subsubsection{Lead to set up correct personal goals}

Target is divided into long-term goals and short-term goals. Teachers should combine their own situation from reality, decompose the ultimate goal and refine the large target, to the extent that knowing what is my goal each day and what effect I need to achieve, so that the goal will become operational and enable teachers to check every day to modify and adjust their goals, and finally achieve their goals in life step by step. Thus they will not be blind panic with any work and anything can be done methodically ${ }^{3}$, On the one hand, they well adjust their mentality and free from the external environment irritability, on the other hand, they can can think calmly and keep a clear head and reflect on themselves three times a day when facing with difficulties.

\subsubsection{Pay attention to the teachers' needs}

Planning of school activities begin from analyzing the needs of teachers involved in school activities. Determining a activity theme that everyone is willing to participate in can help improve the effectiveness of activities, because it allows participants to appreciate at the initial stage that his involvement and investment is likely to improve the status of activities and is also beneficial for their own development. Teacher participating in the activities are sentiment, sometimes even nonrational individuals, if there are no special tools or indicators, their needs are difficult to confirm. But to clarify and identify the different needs of different teachers directly relate to whether the teachers will participate in activities or not and whether activities can be continued or not.

\section{Conclusion}

After making a lot of empirical research, we find that any activity in school and any decision must focus on each teachers' needs. Different individual leads to different leading needs of teachers. Providing teachers with 
leading needs can efficiently improve teachers' working and learning enthusiasm.

\section{References}

[1] Gu Xiaohua, Wang Shouhen,Higher vocational college teachers' job burnout investigation and strategy research,Vocational \& Technical Education Forum, 2010 (13)
[2] Li Ke, Ye Meifen,Higher vocational college teachers' job burnout survey and analysis,Huzhou vocational and technical college journal,2010（3）

[3] Stephen Robbins,Organizational Behavior, Beijing:China Renmin University Press, 2007. 